\title{
THE HYDROGRAPHY AND VENTILATION OF KAU BAY IN HALMAHERA
}

\author{
H.M. VAN AKEN ${ }^{1}$ and $H$. VERBEEK ${ }^{2}$ \\ ${ }^{1}$ Netherlands Institute for Sea Research, P.O. Box 59, 1790 AB Den Burg, Texel, The Netherlands \\ ${ }^{2}$ Institute for Meteorology and Oceanography, P.O. Box 80.005, 3508 TA Utrecht, The Netherlands
}

\begin{abstract}
The hydrography of Kau Bay in Halmahera was studied in 1985 during the Snellius-II Expedition. Contrary to the findings from the Snellius Expedition in 1929-30 the deep water in the bay was not anoxic although very low oxygen concentrations were encountered in the deepest $30 \mathrm{~m}$ of the bay. Rough estimates of the oxygen consumption in the water column and in the sediment indicate that the deep water in the bay is ventilated probably once every year. Within one year the deep water in the bay may become anoxic. This result has been confirmed by estimates of the diffusion time scale of the observed fine structure based on tentative values of the turbulent diffusion coefficient. The flushing appears to be controlled by salinity changes in the surface water of the nearby Pacific Ocean due to shifts of the equatorial current system.
\end{abstract}

\section{INTRODUCTION}

The Kau Bay is a fjord-like bay in the island of Halmahera, situated in northeast Indonesia (Fig. 1). During the Snellius Expedition carried out in 1929-30 it appeared that the deepest $100 \mathrm{~m}$ water in the bay was anoxic (VAN RIEL, 1943). During the IndonesianDutch Snellius-II Expedition R.V. "Tyro" surveyed Kau Bay from 18 to 25 April 1985 in order to study the geology, geochemistry and hydrography (VAN DER LINDEN et al., 1986).

The entrance of the bay is still heavily mined with sea mines from World War II. There is only a narrow swept shipping channel through which deep draught ships can enter the bay safely. Therefore the shallow sill area of the bay hardly has been studied during the survey of R.V. "Tyro".

Several runs with a $3.5 \mathrm{kHz}$ echosounder, a sparker and an air gun have revealed the topography of Kau
Bay as it is shown in Fig. 2a (VAN DER LINDEN et al., 1986). The centre of the bay is quite smooth with a maximum depth of nearly $480 \mathrm{~m}$. The slope which surrounds the deep, smooth part of the bay is steep and cut through by a large number of canyons. The largest and deepest canyon encountered is found in the northeast part of the bay. This canyon is connected directly with the channel towards the sill. The deepest connection across the sill between Kau Bay and the Pacific Ocean has a depth of only about $30 \mathrm{~m}$. The narrow and shallow sill strongly reduces the possibilities for water exchange with the Pacific Ocean and therefore limits the ventilation of the deep water in Kau Bay.

The study presented here has been carried out to obtain a detailed hydrography of the Kau Bay and to find out whether the anoxic deep water observed in 1930 is a permanent feature. With rough estimates of the oxygen consumption in the water column, of the oxygen flux towards the deep sediment and of the turbulent diffusion coefficient, the order of magnitude of the flushing time will be discussed. Some remarks will be made on the controlling mechanism and regularity of the ventilation of the deep parts of the bay.

Acknowledgements.-We thank captain Blok and his crew for their kind cooperation during the cruise and the technicians from $\mathrm{NIOZ}$ and $\mathrm{NRZ}$ for the accurate handling of the CTD-equipment. Wim Boot and Piet Jonker gave technical and computational assistance. This research was supported by the Netherlands Council for Oceanic Research and the Indonesian Institute of Sciences as part of the cooperative Indonesian-Dutch Snellius-II Expedition.

\section{THE DATA}

The data used in this paper were obtained from 19 to 25 April 1985. Wherever it was possible, CTD-stations 


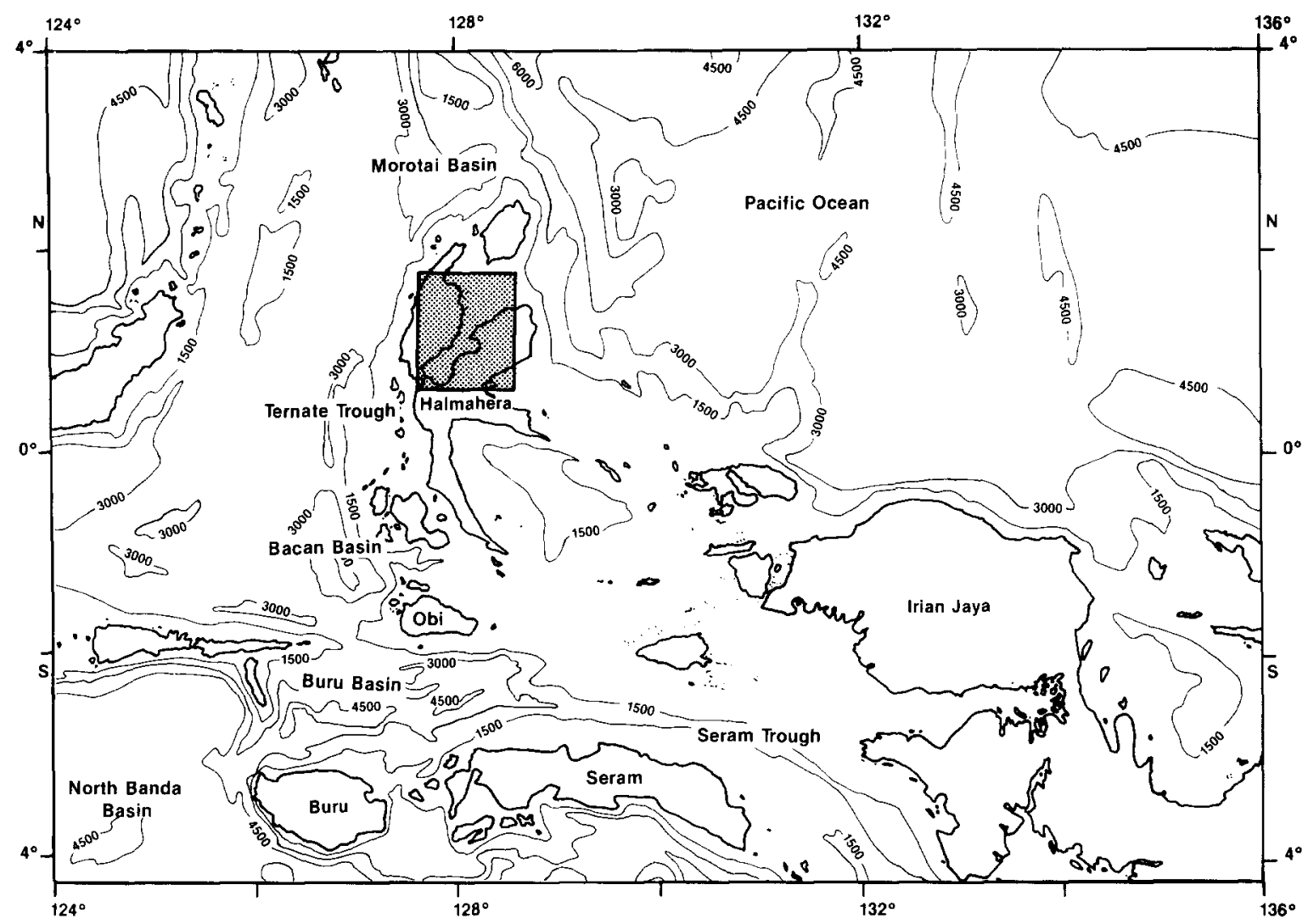

Fig. 1. The topography of the east Indonesian waters. Depth in $\mathrm{m}$. The rectangle indicates the position of Kau Bay in the island of Halmahera.

were occupied in a regular grid with a station distance of about 3 nautical miles (Fig. 2b). One along-bay section within the bay has been occupied twice. In the mine field over the shallow sill area only two CTD-stations were occupied in the mine-free shipping channel. At each station one or more CTDcasts were recorded digitally. At a limited number of stations water samples were taken for the determination of salinity, oxygen concentration and nutrients. With reversing thermometers the quality of the temperature data was controlled. At stations 35 to 53 the CTD was fitted with an oxygen sensor.

At station 34 R.V. "Tyro" was at anchor for over one day so that a time series of 25 hourly CTD-casts was obtained. Also 24 hours of current meter data from a depth of $70 \mathrm{~m}$ were recorded at station 34 . For this purpose a self-recording current meter, fitted with a pressure sensor was used. These data were recorded with a strip chart recorder.

The CTD-data firstly have been de-spiked. Hereafter conductivity, temperature and oxygen con- centration have been corrected with the calibration, obtained from the water samples and the reversing thermometers. Finally the data have been interpolated at 5-m intervals. The accuracy of the temperature is estimated to be $0.01^{\circ} \mathrm{C}$ or better, while the precision of the temperature in the deep water is found to be $0.001^{\circ} \mathrm{C}$ (standard deviation). The accuracy of the practical salinity is estimated to be 0.005 while the precision of the salinity in the deep water is found to be 0.001 (standard deviation). The accuracy of the oxygen concentration, recorded with the oxygen sensor, is estimated to be $5 \mu \mathrm{mol} \cdot \mathrm{dm}^{-3}$. The CTD-data are reported in a data report by VERBEEK (1987a).

The current meter data have been digitized by hand from a strip chart every 2 minutes. The digitized velocity components have been low pass filtered with a Bartlett filter with a width of 18 minutes in order to eliminate the high frequency variability due to the yawing motion of the anchored ship (VERBEeK, 1987b). 


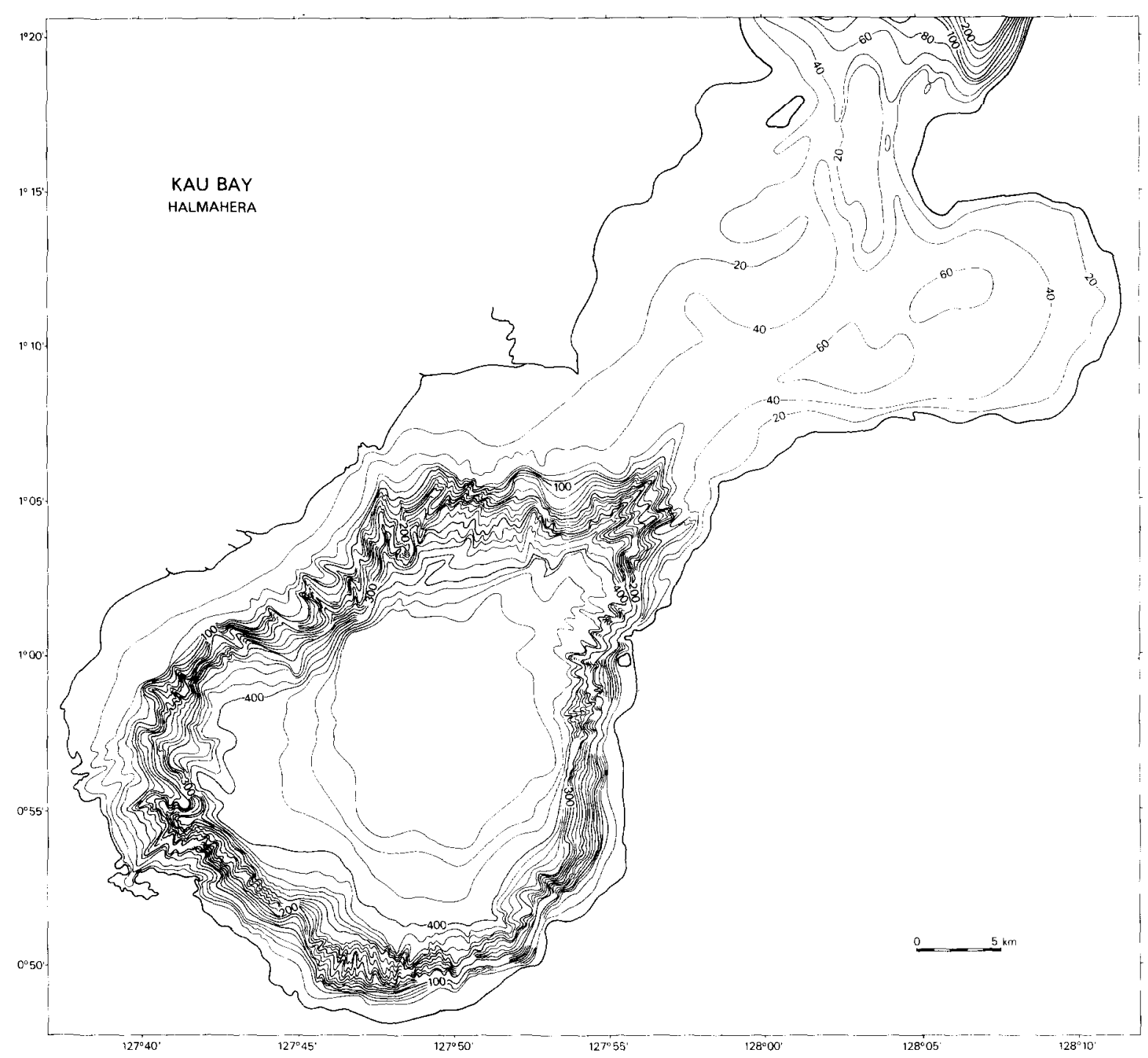

Fig. 2a. The topography of Kau Bay. Depth in m. (source: VAN DER LINDEN et al., 1986)

\section{THE HYDROGRAPHY}

\subsection{INDIVIDUAL PROFILES}

Individual profiles of potential temperature, salinity and potential density in Kau Bay show a characteristic vertical structure. Fig. 3 gives an example from the centre of the bay. Near the sea surface a thin mixed layer overlying a shallow pycnocline is found. In this pycnocline the temperature strongly decreases and the salinity strongly increases to a depth of about $50 \mathrm{~m}$. Between $50 \mathrm{~m}$ and $150 \mathrm{~m}$ smallscale thermohaline fine structure is found with a typical vertical length scale of $20 \mathrm{~m}$. The density fine structure in this layer is mainly correlated with the fine structure in the salinity. Below $150 \mathrm{~m}$ depth the profiles of temperature, salinity and density become smoother since most thermohaline fine structure disappears there. The potential temperature decreases slowly towards the bottom and the salinity slowly increases. The overall density structure is mainly caused by the salinity distribution.

In individual oxygen profiles also a typical characteristic vertical structure is observed (Fig. 4). From the surface to about $150 \mathrm{~m}$ depth the oxygen concentration decreases while between 50 and 


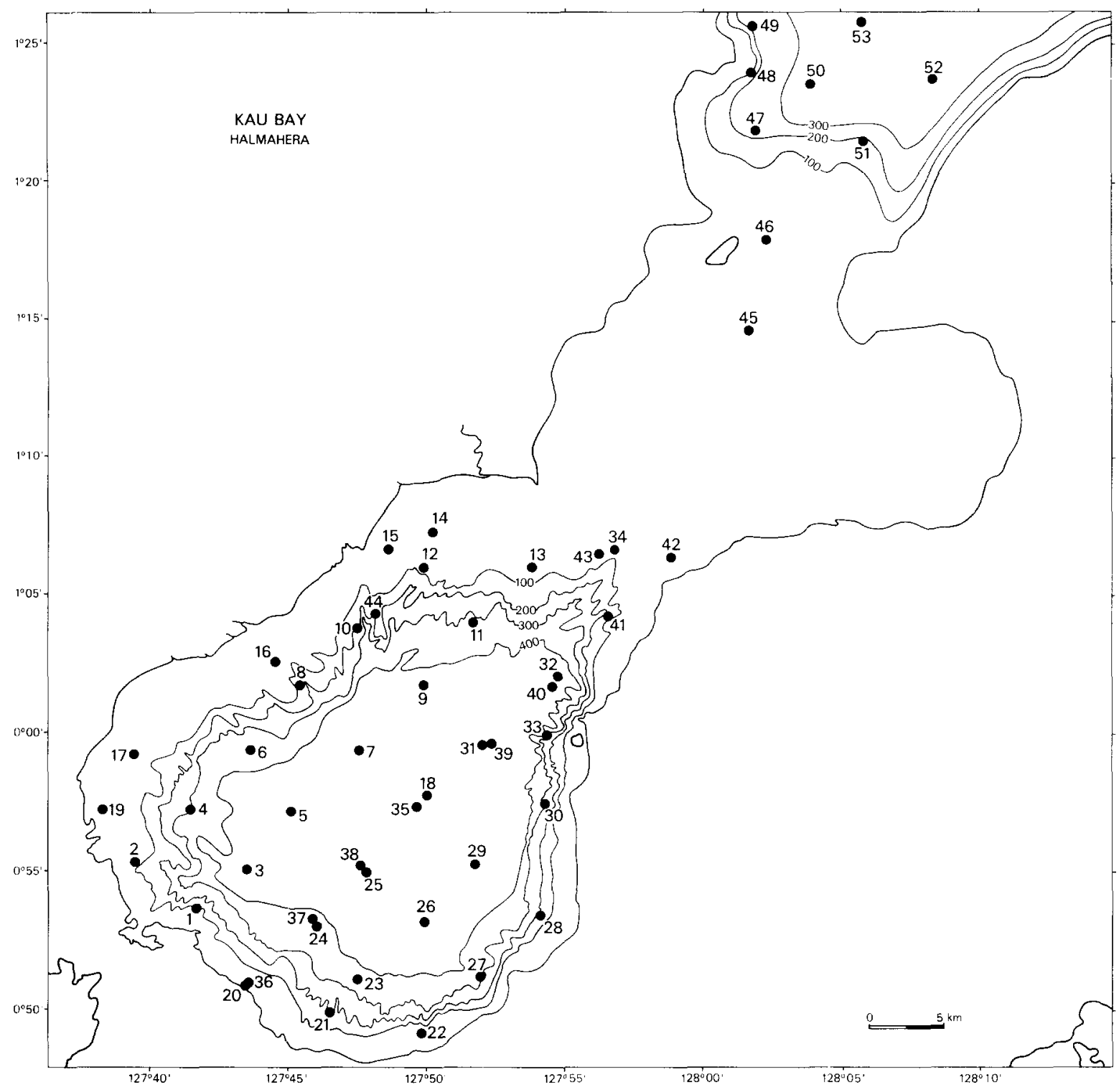

Fig. 2b. Positions of the CTD-stations in Kau Bay. Vertical sections along the indicated lines are given in Figs 8 and 9 . At anchor station 34, time series were recorded.

$150 \mathrm{~m}$ fine structure is observed with a typical vertical length scale of about $20 \mathrm{~m}$, the same scale as is found for the thermohaline fine structure. From a depth of $150 \mathrm{~m}$ towards $350 \mathrm{~m}$ the oxygen concentration shows a slightly increasing trend while below $350 \mathrm{~m}$ the oxygen concentration decreases to about $60 \mu \mathrm{mol} \cdot \mathrm{dm}^{-3}$ at $440 \mathrm{~m}$ and to very low values of the order of $10 \mu \mathrm{mol} \cdot \mathrm{dm}^{-3}$ near the bottom. Nowhere near the bottom of the bay has anoxic water been observed. In the whole depth range between $150 \mathrm{~m}$ and $440 \mathrm{~m}$, fine structure is observed with a typical vertical length scale of about $50 \mathrm{~m}$ and with a typical magnitude of $10 \mu \mathrm{mol} \cdot \mathrm{dm}^{-3}$

Diagrams of potential temperature versus salinity and of oxygen concentration versus salinity for an individual station (Fig. 5) seem to show some correlation between temperature and oxygen fine structure. However no definite coherence between temperature and oxygen can be established.

Profiles of the Brunt-Väisälä frequency (Fig. 6) reveal variations of the static stability due to the density fine structure. Everywhere in the water column, 


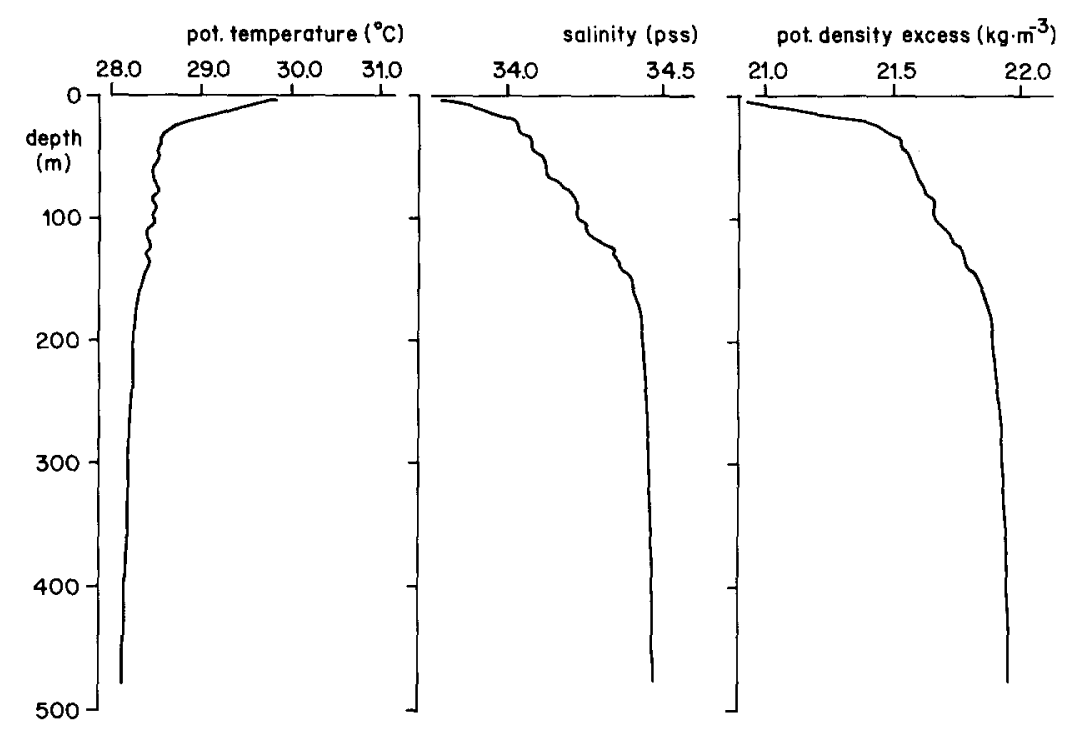

Fig. 3. Profiles of potential temperature, salinity and potential density excess at station 35 .

smoothed over $10 \mathrm{~m}$, the water column appears to be stable. The mean Brunt-Väisälä frequency decreases from $8 \cdot 10^{-3} \mathrm{~Hz}$ in the upper $60 \mathrm{~m}$ to $1 \cdot 10^{-3} \mathrm{~Hz}$ in the deepest $100 \mathrm{~m}$. This implies that everywhere in the bay diurnal and semi-diurnal internal tides can propagate as free waves.

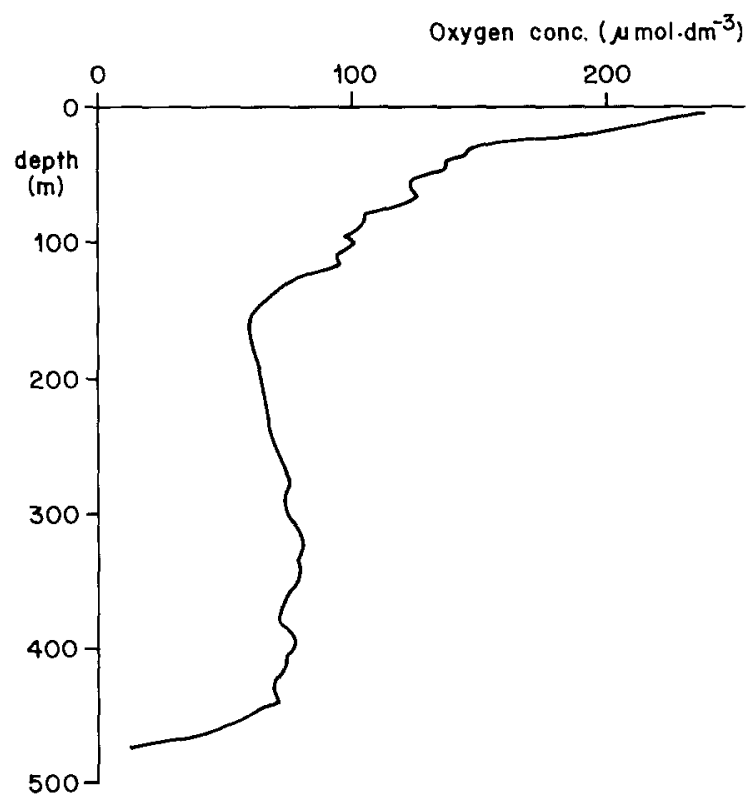

Fig. 4. Profile of oxygen concentration at station 35 .

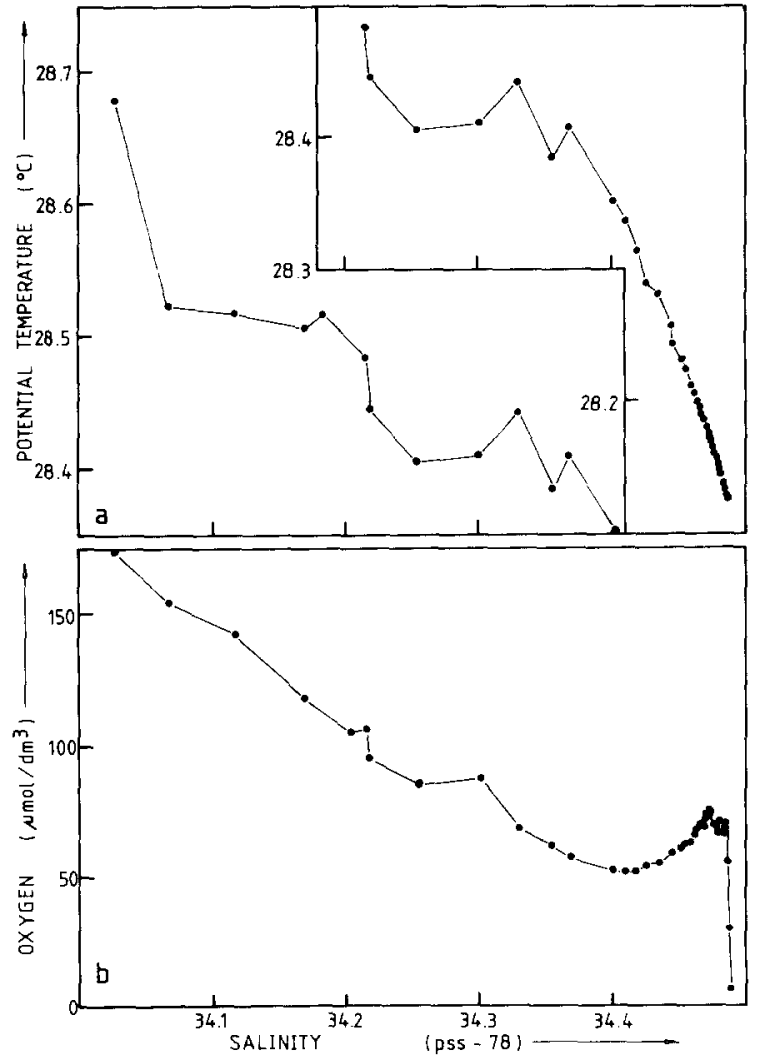

Fig. 5. Potential temperature-salinity diagram (a) and oxygen-salinity diagram (b) for station 35 . These diagrams are based on low pass filtered $10 \mathrm{~m}$ values. 


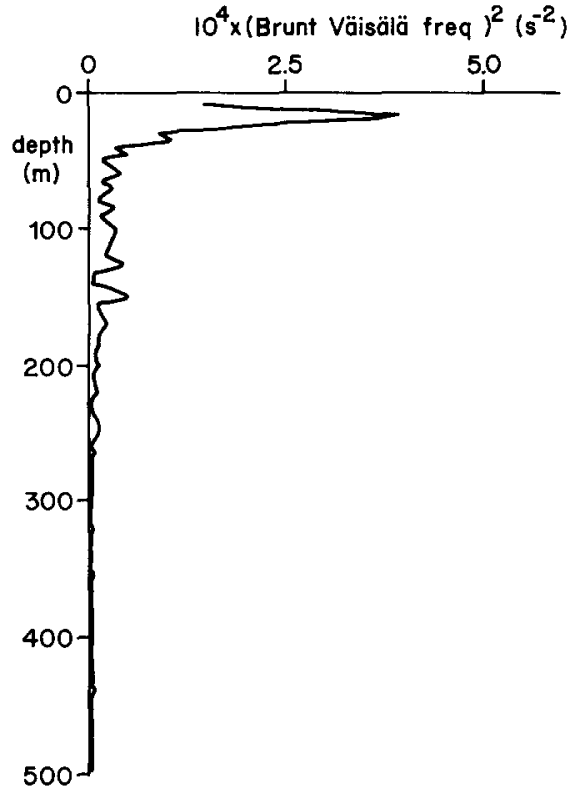

Fig. 6. Profile of the Brunt-Väisälä frequency at station 18. This profile is based on $10 \mathrm{~m}$ low pass filtered data.

The repeated CTD-casts at nearby positions in the repeated along-bay section, shown in Fig. $2 \mathrm{~b}$, often show strong temporal variations in the observed profiles. The profiles from station 40 have been recorded 68 hours after the profiles from station 32 at a mutual

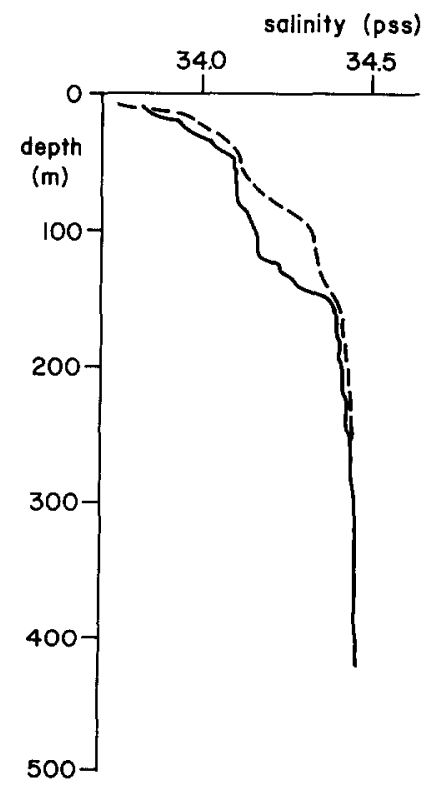

Fig. 7. Profiles of salinity at the nearly coinciding stations $\mathbf{3 2}$ $(-)$ and $40(---)$. horizontal distance of less than $400 \mathrm{~m}$. Strong differences between both stations can be observed in the uppermost $200 \mathrm{~m}$ (Fig. 7). The large steplike structure, observed at station 32 can be obtained by vertical deformation of the smooth profile from station 40 due to vertical displacement of isolines of over $50 \mathrm{~m}$.
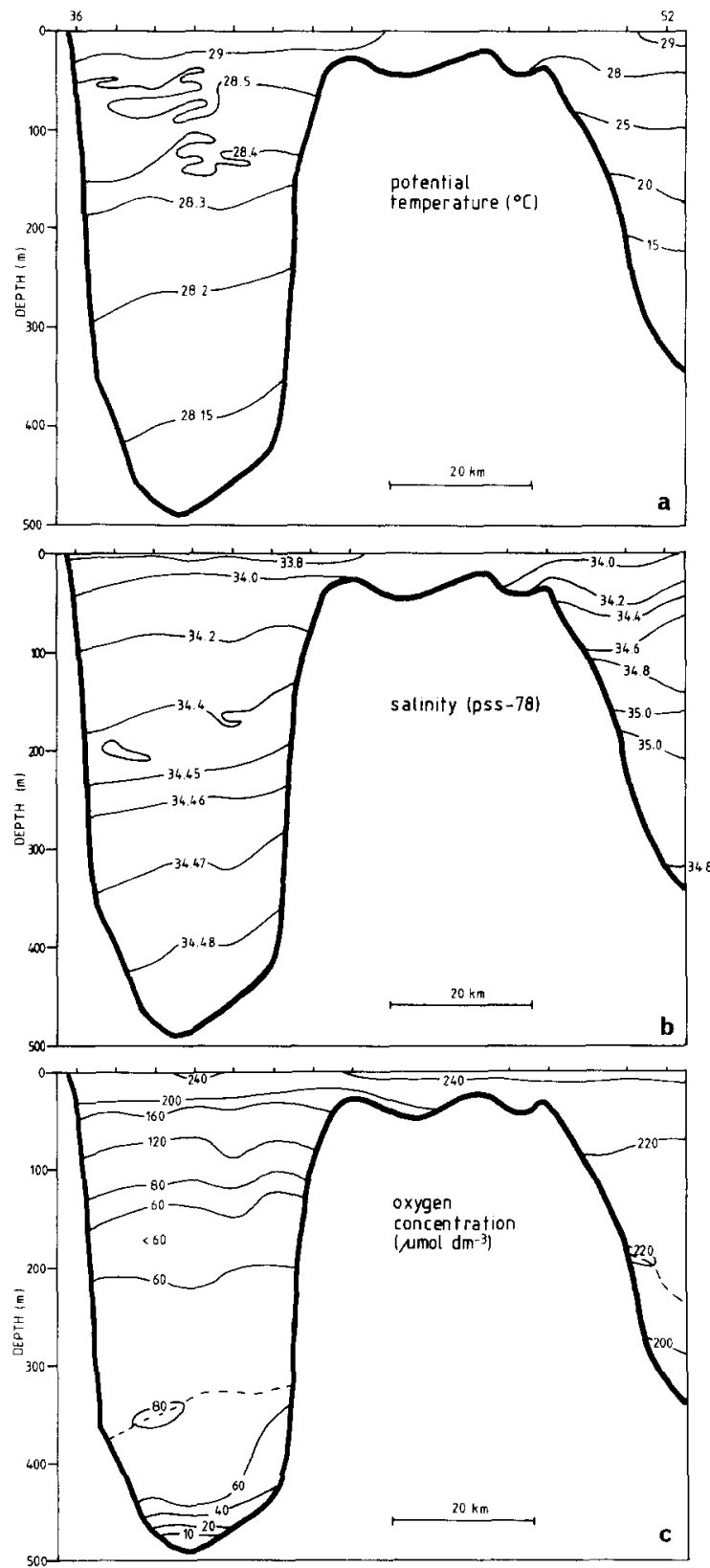

Fig. 8. Vertical sections of potential temperature (a), salinity (b) and oxygen concentration (c) from the end of the bay (station 36 ) to outside the bay (station 52 ). The line connecting these stations is drawn in Fig. $2 b$. 

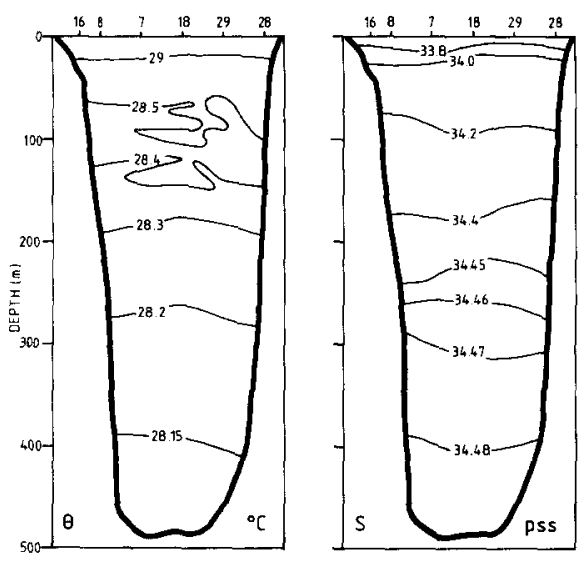

Fig. 9. Vertical sections of potential temperature (a) and salinity (b) across the bay. The line connecting the stations is drawn in Fig. $2 b$.

\subsection{DISTRIBUTION OF PROPERTIES IN THE BAY}

Water with the temperature range observed within the bay is found outside the bay, north of the sill area at depths of less than $50 \mathrm{~m}$ (Fig. 8a). The salinity values, found in the bay below $100 \mathrm{~m}$ are observed outside the bay in the depth interval from 50 to $80 \mathrm{~m}$ (Fig. 8b). Because of the shallow sill, no direct connection between the deep water in the bay and the water outside the bay with the same properties can be observed.

Vertical sections in the along-bay direction and perpendicular to that direction show the presence of fine structure in the temperature field between depths of 50 and of $150 \mathrm{~m}$, at several positions in the bay (Figs $8 \mathrm{a}$ and $9 \mathrm{a}$ ). This thermohaline fine structure, which has been described above for individual profiles, can hardly be observed in the salinity sections (Figs $8 \mathrm{~b}$ and $9 \mathrm{~b}$ ). This is caused by the regular presence of inversions of the temperature gradient, while, due to the stronger background salinity gradient, the salinity nearly always increases downward, despite the presence of fine structure in the salinity field. The horizontal scale of the thermohaline fine structure appears to have a typical horizontal scale of 10-15 km (Figs 8a and 9a).

The along-bay oxygen section (Fig. $8 \mathrm{c}$ ) reveals that the oxygen minimum at depths between 150 and $200 \mathrm{~m}$ is a feature found throughout the bay. Also the oxygen maximum at about $350 \mathrm{~m}$ is found at all stations within the bay. At all deep stations in the bay a strong oxygen minimum was observed near the bottom, but only at one station was the minimum concentration below $10 \mu \mathrm{mol} \cdot \mathrm{dm}^{-3}$. Within the bay at all depths below about $20 \mathrm{~m}$ the water in Kau Bay has a strong oxygen deficit compared with the Pacific water outside the bay at the same depths (Fig. 8c).

In the upper $20 \mathrm{~m}$ the observed silica concentrations are always below the detection level of $5 \mu \mathrm{mol} \cdot \mathrm{dm}^{-3}$. The observed silica concentrations below the surface layer are relatively high for the depth levels involved (Fig. 10a). Between $200 \mathrm{~m}$ and $300 \mathrm{~m}$ depth the silica concentration is nearly constant. Above $200 \mathrm{~m}$ and below $350 \mathrm{~m}$ depth, the silica concentration increases with depth (Fig. 10a). Since the inflow over the sill occurs as surface water less

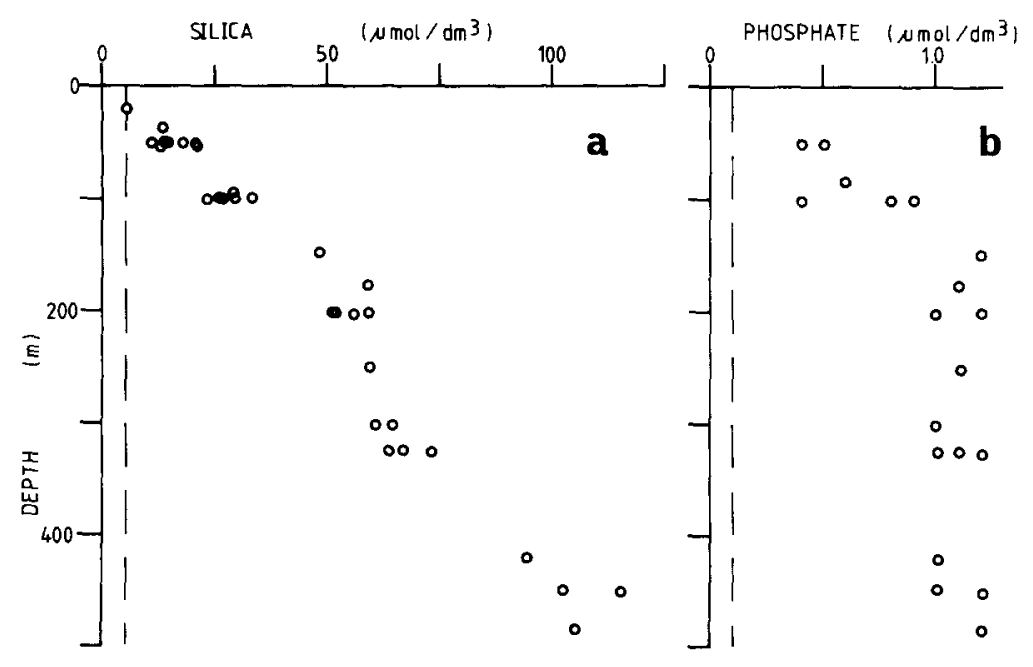

Fig. 10. Profiles of all determined silica concentrations (a) and phosphate concentrations (b). The dashed lines indicate the detection levels. 

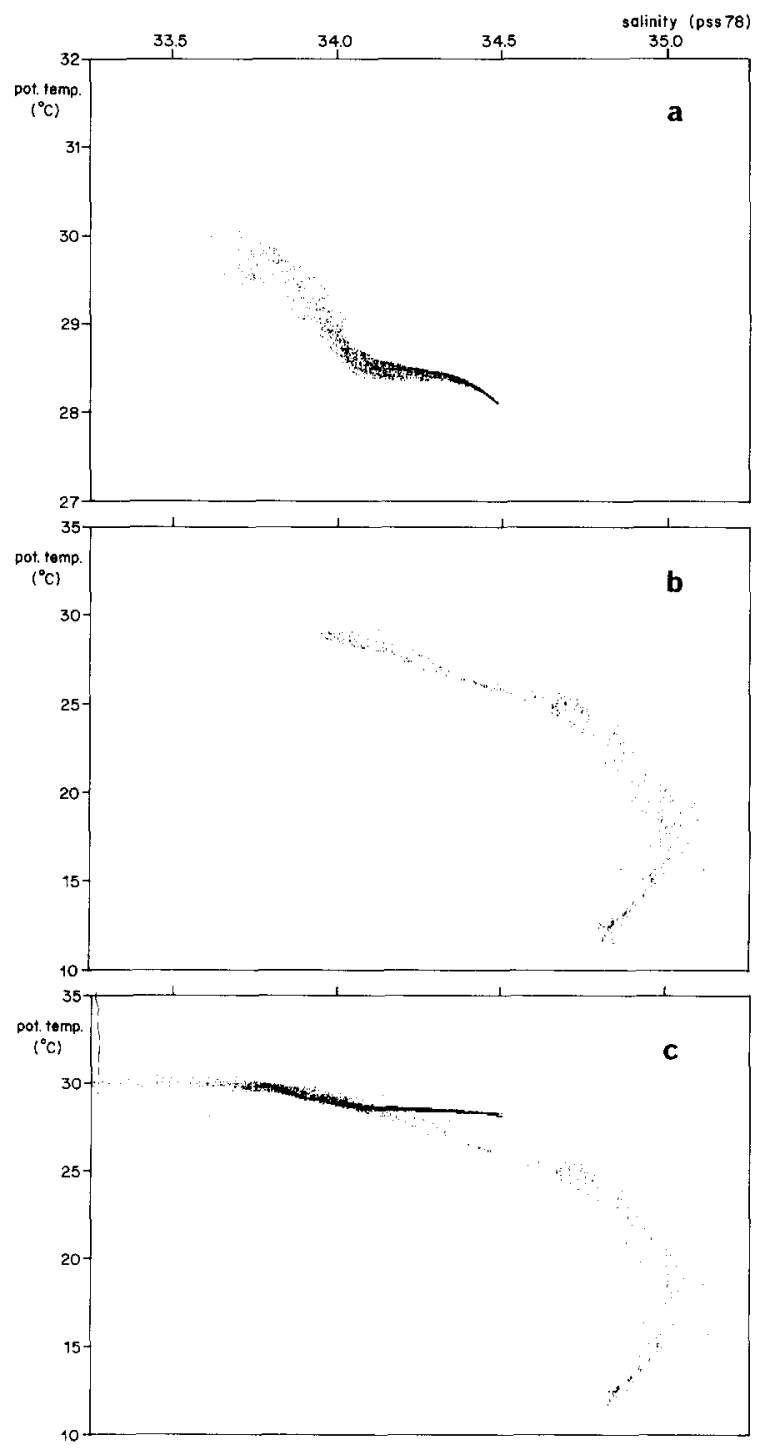

Fig. 11. Potential temperature-salinity diagrams for all stations within Kau Bay (a), all stations outside the bay (b) and all stations combined (c)

than $30 \mathrm{~m}$ deep, it is expected that nearly all silica observed in Kau Bay originates from local dissolution and from sediment water interaction. The vertical gradient in the upper $200 \mathrm{~m}$ of the bay indicates a turbulent flux into the photic zone where silica is taken up by diatoms. The more or less constant silica concentration between $200 \mathrm{~m}$ and $350 \mathrm{~m}$ depth is caused by local dissolution of silica which rains down in dead diatoms and faecal pellets. The gradient in the deepest $150 \mathrm{~m}$ of the bay is probably caused by a silica flux from the sediment towards the overlying water (Fig. 10a).
The observed phosphate concentrations (Fig. 10b) are also below the detection level $\left(0.1 \mu \mathrm{mol} \cdot \mathrm{dm}^{-3}\right)$ in the surface layer. Below $150 \mathrm{~m}$ depth the phosphate concentration is nearly constant. No strong phosphate gradient near the bottom is observed.

Water-mass analysis by means of potential temperature-salinity diagrams reveals that the water properties are found in a narrow band within the bay (Fig. 11a) as well as outside the bay (Fig. 11b). However, the combination of both diagrams into one shows that the water-mass properties found within the bay below the 34.1 isohaline (about $50 \mathrm{~m}$ ) have not been observed outside the sill area (Fig. 11c). In the main body of water inside the bay a salinity excess of about 0.35 is observed.

\subsection{TIME SERIES}

From the CTD-casts, recorded at the anchor station (34) situated in the large canyon near the sill area, a time depth section of the salinity can be constructed (Fig. 12). This section reveals a strong semi-diurnal variation of the salinity. The isohalines show vertical excursions of about $20 \mathrm{~m}$ at mid-depth, but the 34.4 isohaline, observed every 12 hours, is found within the bay at a depth of $170 \mathrm{~m}$ (Figs $8 \mathrm{~b}$ and 9b). The current in the canyon direction $\left(029^{\circ}-209^{\circ}\right)$ at a depth of $70 \mathrm{~m}$ appears to be $90^{\circ}$ out of phase with the salinity at the same depth (Fig. 13). The salinity increases during outflow towards the sill and decreases during inflow. This indicates that the observed semi-diurnal variation has a wave-like character, most probably caused by internal tides. The sharply peaked outflow (Fig. 13) and also the sharp changes in the salinity field (Fig. 12) show that the wave has a non-linear character. These non-linearities are probably caused by the non-linear surging of the internal tide into the wedge-shaped canyon. Such surging can also explain the very large vertical excursion of the 34.4

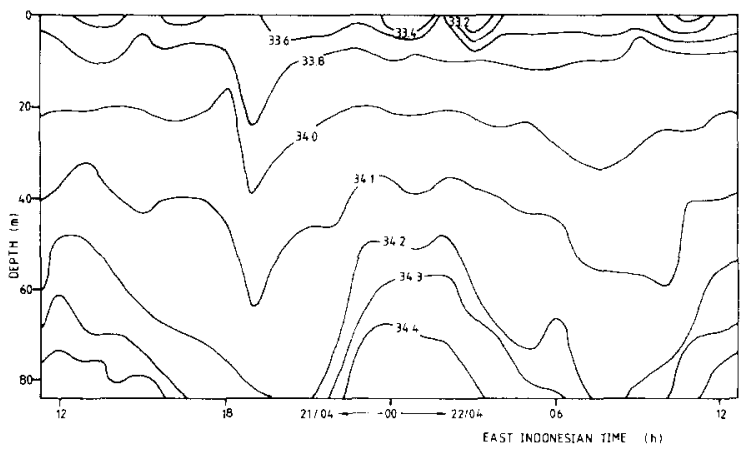

Fig. 12. Time-depth section of the practical salinity observed at station 34 . The local depth is $85 \mathrm{~m}$. 


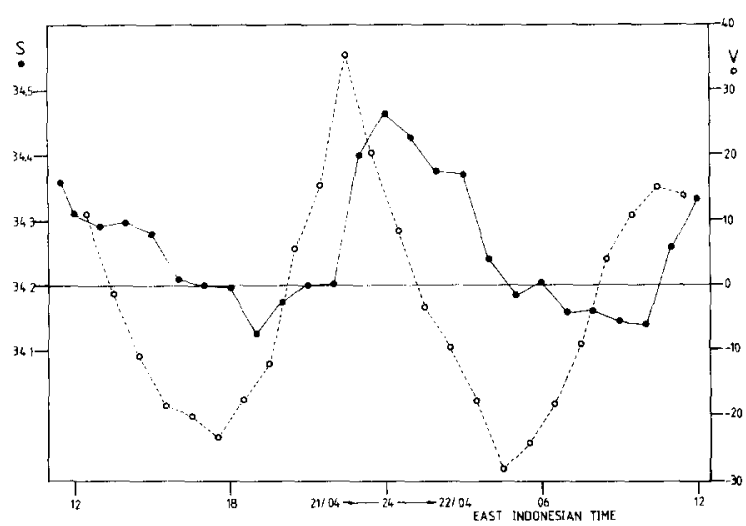

Fig. 13. Time series of the velocity in $\mathrm{cm} \cdot \mathrm{s}^{-1}$, in the direction $029^{\circ}(0)$ and of the practical salinity $(\bullet)$, both observed at station 34 at a depth of $70 \mathrm{~m}$.

isohaline and also the large vertical excursion observed at stations 32 and 40 at the bay side end of the canyon (Fig. 7).

\section{DISCUSSION AND CONCLUSIONS}

In a stratified fjord-like basin like Kau Bay, water properties can change by the inflow of water from outside the basin across a shallow sill, by sediment water interaction, by sources and sinks in the water column and by turbulent mixing. The turbulent transport has mainly a vertical component and is generally computed from the product of an eddy diffusion coefficient and the vertical gradient of the property. For the eddy diffusion coefficient, $K$, in Byfjorden in Sweden SVENSSON (1980) has found a dependence from the Brunt-Väisälä frequency, $N$, described by:

$$
K\left(\mathrm{~m}^{2} \cdot \mathrm{s}^{-1}\right)=1.2 \cdot\left(\mathrm{N}^{2}\right)^{-0.6}
$$

For Kau Bay, $K$ has been computed according to (1) for different depth intervals. The result is shown in Fig. 14. SMETHIE (1980) made clear that (1) gives a lower boundary estimate for $K$ in different fjords, while the actual eddy diffusion coefficients happened to be larger, up to over a factor 10. This suggests that applied to Kau Bay, $K$ may vary from $K=4 \cdot 10^{-6}$ $4 \cdot 10^{-5} \mathrm{~m}^{2} \cdot \mathrm{s}^{-1}$ in the surface layer to $K=4 \cdot 10^{-5}$ $4 \cdot 10^{-4} \mathrm{~m}^{2} \cdot \mathrm{s}^{-1}$ in the lowest $200 \mathrm{~m}$. With the $K$ values according to SVENSSON (1980) (Fig. 14) as a lower boundary of a one order of magnitude range for $K$, the order of magnitude of turbulent vertical fluxes of oxygen and other properties can be determined.

The energy which is needed to maintain the tur-

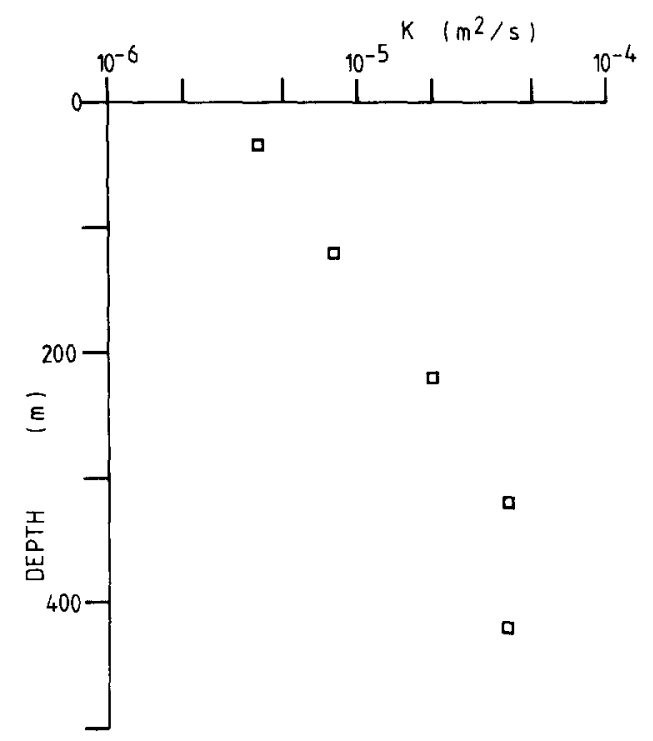

Fig. 14. Profile of the mean eddy diffusion coefficient in Kau Bay, determined from (1). These values are assumed to be the lower boundary of a one order of magnitude range for the actual values of the diffusion coefficient.

bulence in the stratified water of Kau Bay is most probably derived from the internal tides. As described above, internal tidal waves surge in the canyons which surround the deep parts of the bay so that relatively large velocities are observed in these canyons. Turbulence will be generated in these canyons where near bottom shears occur.

The typical time scale, $\tau$, with which structures with a vertical length scale, $L$, will be reduced by a factor $e$, by turbulent diffusion, is estimated to be:

$$
\tau=L^{2} / K
$$

Transient structures observed in Kau Bay will have an age, $t$, which is generally less than $\tau$. For stationary structures one can assume that these structures are generated by processes with typical time scales $\mathrm{t}<<\tau$. The typical diffusion time scale for the large scale stratification in Kau Bay appears to be 40-400 years, according to (2). Flushing events, generating the observed large scale stratification, are therefore assumed to occur much more often than once every 40-400 years.

The hydrography of Kau Bay appears to have changed since the Snellius Expedition of 1929-30. The anoxic situation in the deep water (VAN RIEL, 1943) has changed to an oxygenated one with only a less than $30 \mathrm{~m}$ thick layer with near-bottom oxygen concentrations of about $10 \mu \mathrm{mol} \cdot \mathrm{dm}^{-3}$ in 1985 . Com- 
parison of temperature and salinity data from 1930 (VAN RIEL et al., 1957) with the data reported here reveals that since 1930 the temperature below $200 \mathrm{~m}$ has decreased with about $0.04^{\circ} \mathrm{C}$ and the salinity below $200 \mathrm{~m}$ has increased by about 0.03 . These changes cannot be caused by bottom heat flow, turbulent mixing by the warmer and fresher surface water or sediment water exchange of oxygen. This leads inevitably to the conclusion that the deep water in Kau Bay has been ventilated by inflow of Pacific surface water since 1930 .

The observed hydrography and water mass properties indicate that during the survey no continuous inflow into the bay has occurred. Therefore one can conclude that flushing of the Kau Bay does not take place as a continuous process but as one or more distinct events. Such a flushing event has occurred at least once between 1930 and 1985 .

In order to obtain a more precise estimate of the rate of flushing events, we have to study the oxygen budget of the water in the bay in a more quantitative way. We assume that whenever the bay is flushed, the water which enters the bay over the shallow sill is more or less saturated with oxygen. This implies an oxygen content of about $210 \mu \mathrm{mol} \cdot \mathrm{dm}^{-3}$. This gives a mean oxygen deficit in the water column of about $130 \mu \mathrm{mol} \cdot \mathrm{dm}^{-3}$. In order to find out how long it takes to build up that deficiency, estimates of the respiration rate in the water column and of the oxygen flux into the sediment are needed.

From the presence of large numbers of diatoms and high numbers of faecal pellets in the deep-water sediment of Kau Bay and from the large turbidity of the surface water, high surface-water productivity is derived (VAN DER LINDEN et al., 1986). Such high productivity in the surface waters will cause a high respiration rate in the water column and a large oxygen demand from the sediment. For a highly productive open ocean situation in the nearby eastern Banda Sea VosJAN et al. (in press) determined a mean respiration rate in the upper $300 \mathrm{~m}$ of $0.6 \mu \mathrm{mol}$ $\mathrm{O}_{2} \cdot \mathrm{dm}^{-3} \cdot \mathrm{d}^{-1}$. Because the respiration rate in Kau Bay will be augmented by import of terrestial organic matter from the surrounding land, we will use the above given number as a roughly estimated lower boundary of the actual mean local respiration rate.

For the deep Savu (=Sawu) Basin, Helder (pers. comm.) has determined the oxygen flux into the sediment to have values between 10 and $30 \mathrm{mmol} \cdot \mathrm{m}^{-2} \cdot \mathrm{d}^{-1}$. Helder ascribes these high values to the run-off of organic matter from the islands which surround the Savu Basin. Since Kau Bay is smaller and shallower than the Savu Basin it is expected that relatively more organic matter from the surrounding land and from the productive surface layers will reach the bottom of Kau Bay. Therefore we will use the higher value of the Savu Basin, i.e. $30 \mathrm{mmol} \cdot \mathrm{m}^{-2} \cdot \mathrm{d}^{-1}$ as a lower boundary estimate for the oxygen flux into the sediment.

From these estimates of the oxygen consumption one can derive upper boundaries for the time needed to generate the observed oxygen deficiencies. With the eddy diffusion coefficient discussed above, the order of magnitude of the turbulent oxygen flux has been determined. It appears that the turbulent diffusion of oxygen from the surface layer into the interior of the bay can be neglected, compared with the other terms of the oxygen budget. The age of the deep water in the bay has turned out to be 6 months or less, if during a flushing event all water is totally replaced by saturated surface water. The generation of the overall oxygen deficit appears to be caused mainly by the local oxygen consumption in the water column.

By the same method, the age of the near-bottom low oxygen layer has been determined to be about 4 months. In the generation of this bottom layer the estimated oxygen flux into the bottom has caused 60 percent of the total deficit. However, the neglected turbulent flux of oxygen from the overlying layers appears to be not negligible compared with the bottom flux, so that the actual age of the low-oxygen bottom layer may be larger than 4 months.

The age estimates of the oxygen deficiency given above are based on rough but informed guesses of the oxygen consumption in the water column and in the sediment. Since these are upper boundary estimates, it can be concluded that the time needed to generate the observed oxygen distribution is most probably below one year. The overall vertical structure of the oxygen distribution is caused by the vertical distribution of the respiration rate and of the vertical turbulent fluxes as well as by the sedimentwater interaction. The smaller-scale fine structure is thought to be caused by modulation of the inflow as is discussed below.

The observed salinity in the deep parts of the bay reveal that during the previous flushing event the surface water outside the bay had a salinity of at least nearly 34.5. This is about 0.5 higher than the actual surface salinity over and north of the sill. However, the annual mean surface salinity near Halmahera, outside Kau Bay, is 34.2 , with an annual variation from 33.85 in March to 34.55 in October (WYRTKI, 1961). Wyrtki ascribes the annual variation, as well as large amplitude variations with higher frequencies, to the shifting position of the front between the South Equatorial Current and the Equatorial Counter Cur- 
rent. Flushing will most probably occur if the salinity in the upper $30 \mathrm{~m}$ outside Kau Bay has a maximum value, that is in October. This agrees with the estimated time since the last flushing event, viz. 6 months. However, the variations of the surface salinity with higher frequencies mentioned by Wyrtki, may complicate this scheme. But at least one can conclude that the flushing events probably are related to the variation of the salinity near the sea surface in the nearby Pacific Ocean. This variation is caused by shifts in the position of the equatorial current system with annual and higher frequencies.

The observed fine structure of temperature, salinity and oxygen may be caused by the inflow of limited amounts of water. Due to the temporally and vertically slowly varying initial properties of the inflowing water and due to mixing during inflow, ultimately this water will reach a level in the bay where its density is adapted to the density stratification within the bay. That level is not necessarily the bottom. Tidal and meteorological modulation of the inflow may cause whole series of smaller inflow events within a larger scale flushing event. Each small inflow event may cause a distinct thin layer which can be observed as fine structure. After the flushing of the bay this fine structure will be eroded by turbulent diffusion. The diffusion time scale of the observed fine structure has been determined according to (2) with the estimated diffusion coefficients discussed above. The resulting diffusion time scale of the thermohaline fine structure between 50 and $150 \mathrm{~m}$ depth turns out to be 50-500 days. The diffusion time scale for the deep oxygen fine structure appears to be $100-1000$ days. These rough estimates do not contradict the assumption that the age of the observed fine structure is the same as the apparent age of the deep water since the last flushing event, viz. about 6 months.

Summarizing it can be concluded that Kau Bay is intermittently flushed. Flushing events may occur probably at least once every year due to the variability of the properties of the Pacific surface water near Halmahera. Due to the large fertility of the surface water within the bay and due to the import from the surrounding land into the bay of terrestial organic matter, the oxygen consumption in the deep water and in the bottom sediment is assumed to be large. This large oxygen consumption may easily lead to low oxygen concentrations and even to anoxic situations in the deep-near bottom layers of the bay. So, the anoxic bottom layer observed in 1930 as well as the oxygenated situation observed in 1985, are probably both not exceptional situations. Confirmation of these conclusions may be obtained from small surveys in Kau Bay, repeated every three months for at least one year.

\section{REFERENCES}

LINDEN, W.J.M. VAN DER, S. HARTSUKOHARDJO, W.J. ZACHARIASSE \& G.J. DE LANGE, 1986. Theme 1, Geology and Geophysics of the Banda Arc, Cruise G4, Banda, Seram, Halmahera and Maluku Sea, Kau Bay. The Snellius-II Expedition, Progress Report.

RIEL, P.M. VAN, 1943. The bottom water, introductory remarks and oxygen content.-Snellius Exped. 1929-1930. Vol II, part 5, Chapter I. E.J. Brill, Leiden: 1-77.

Riel, P.M. VAN, P. GRoen \& M.P.H. Weenink, 1957. Quantitative data concerning the statics of the EastIndonesian waters. Depths of standard pressures and stability values.-Snellius Exped. 1929-1930. Vol II, part 7. E.J. Brill, Leiden: $1-45$.

SMETHIE, W.M., 1980. Estimation of vertical mixing rates in fjords using naturally occurring Radon-222 and salinity as tracers. In: H.J. FREELAND, D.M. FARMER \& C.D. LEWIS. Fjord Oceanography. Plenum, New York: 241-249.

SVENSSON, T., 1980. Tracer measurement of mixing in the deep water of a small, stratified sill fjord. In: H.J. FREelAND, D.M. FARMER \& C.D. LEWIS. Fjord Oceanography. Plenum, New York: 233-240.

VERBEEK, H., 1987a. Data report on the CTD-casts of the Kau Bay, the Snellius-II Expedition.-Institute for Meteorology and Oceanography, Utrecht University, report R87-6: 1-177.

_- 1987b. Hydrography and renewal of the Kau Bay, the Snellius-II Expedition.-Institute for Meteorology and Oceanography, Utrecht University, report R87-7: 1-62.

Vosjan, J.H., G. Nieuwland \& Ruyitno, in press. Monsoonal differences in microbial biomass, respiratory activity and bacterial numbers in the Banda Sea.Proc. Snellius-II symp. Neth. J. Sea Res.

WYRTKI, K., 1961. Physical oceanography of the southeast Asian waters. Naga Rep., Scripps Inst. Oceanogr: 1-195. 